\title{
Abnormal intestinal permeability and jejunal morphometry
}

\author{
L D JUBY, M F DIXON,* A T R AXON
}

From the Gastroenterology Unit and *University Department of Pathology, General Infirmary, Leeds

SUMMARY The cellobiose and mannitol differential sugar test is a non-invasive investigation of small bowel permeability, in which urinary recoveries of cellobiose and mannitol after a hyperosmolar oral load are expressed as a ratio to give a permeability index. Changes in the cellobiose:mannitol ratio often occur in coeliac disease, but some patients with abnormal permeability have normal jejunums by routine microscopy. Using computed morphometry the perimeter:lamina propria area index of jejunal biopsy samples was measured and compared with the cellobiose:mannitol ratio in three groups of patients: (i) those with coeliac disease with villous atrophy; (ii) those with normal jejunums and sugar test results: and (iii) those with normal jejunums but abnormal sugar test results. In addition to the expected difference in perimeter:lamina propria area index between patients with coeliac disease and those with normal findings $(p<0.001)$, the index was also abnormal in patients with normal jejunums but abnormal sugar test results: ( $p<0.001$ compared with group 1$)$ and $(0.01>p>0.001$ compared with group 2$)$. There was a significant overall correlation between the perimeter:lamina propria area index and cellobiose:mannitol ratio ( $\mathrm{p}=0.001)$. This study shows that computed jejunal morphometry can identify patients with subtle morphological changes that are related to abnormal intestinal permeability.

Changes in intestinal permeability often occur in coeliac disease, where there is increased passive absorption of large molecules and decreased absorption of small molecules. ${ }^{12}$ An absorption test using cellobiose, a disaccharide (molecular radius $5 \AA$ ), as the large molecule, and mannitol, a polyhydric alcohol (molecular radius $4 \AA$ ), as the small molecule differentiates between patients with villous atrophy and those with normal jejunums. ${ }^{13}$

We performed more than 1000 cellobiose and mannitol sugar tests in our department over a period of seven years. On the basis of these tests we found 54 patients with evidence of abnormal permeability and symptoms suggestive of coeliac disease, but with jejunums that seemed to be normal on routine histological examination. Strobel et al found a similar group of patients in whom abnormal permeability was associated with a high intraepithelial lymphocyte count but with normal villi and crypts. ${ }^{4}$

In an attempt to determine whether or not these patients have a truly normal mucosal architecture we

Accepted for publication 19 February 1987 have undertaken morphometry, using computerised image analysis ${ }^{5}$ on jejunal biopsy samples from three groups of patients: (i) those with recently diagnosed coeliac disease with villous atrophy before treatment with a gluten free diet; (ii) those with normal permeability and normal jejunums; (iii) those with abnormal permeability but "normal" jejunums.

\section{Patients and methods}

\section{PATIENTS}

Ten patients (nine women, one man) who had recently diagnosed coeliac disease as shown by severe crypt hyperplastic villous atrophy on jejunal biopsy specimen were studied. Twenty patients ( 12 women, eight men) had symptoms suggestive of coeliac disease on presentation (five with weight loss, 11 with diarrhoea, two with abdominal pain, one with iron deficiency anaemia, one with oral aphthous ulceration), but had normal villous architecture with no increase in either lamina propria chronic inflammatory cells or intraepithelial lymphocytes on routine microscopical examination. Of these patients, 10 had normal cellobiose and mannitol test results 
and 10 had abnormal results. These patients were chosen as they had well orientated jejunal biopsy specimens.

\section{BIOPSY SPECIMENS AND CELLOBIOSE AND}

\section{MANNITOL TEST}

Jejunal biopsy specimens were taken with a Watson biopsy capsule under $x$-ray control when the capsule had reached the ligament of Treitz.

The cellobiose and mannitol test entailed drinking a solution containing $5 \mathrm{~g}$ of cellobiose and $2 \mathrm{~g}$ of mannitol dissolved in $100 \mathrm{ml}$ of water and made hypertonic with $20 \mathrm{~g}$ of lactose and $20 \mathrm{~g}$ of sucrose to $1500 \mathrm{~m} 0 \mathrm{smol}$; this increases cellobiose absorption and enhances the differences between normal subjects and patients with coeliac disease. ${ }^{67}$ As this solution is supersaturated with regard to lactose, crystals occasionally form, but these may be dissolved by gently warming the solution container in warm water. A control specimen of urine was collected after the patient had fasted for six hours and immediately before he or she ingested the solution. After ingestion all urine was collected for the next five hours into $1 \mathrm{ml}$ of $1 \%$ thiomersal as a preservative; if the urine was to be analysed after 24 hours it was stored at $-20^{\circ} \mathrm{C}$.

\section{ASSA YS}

Mannitol was assayed by a spectrophotometric method and cellobiose by paper chromatography. ${ }^{89}$ The urine recovery was expressed as the percentage of the administered dose recovered, and the cellobiose and mannitol recovery ratio was the ratio of the percentage of each probe molecule recovered (normal range $0 \cdot 004-0 \cdot 028$ ).

\section{JEJUNAL MORPHOMETRY}

By means of Jung Kontron IBAS image analyser in the interactive mode (IBAS2) ${ }^{5}$ the perimeter and the lamina propria area of a fixed field of jejunum were measured by drawing with the cursor on a digitising tablet around the perimeter of the villi, the cut margins, and superficial aspect of the muscularis mucosae as displayed on the visual display unit (fig 1). The lamina propria area was measured by tracing around the basement membrane of the epithelium, cut margins, and muscularis mucosae and editing out any cross sectioned crypts (fig 2). These measurements were performed on three random fields from each biopsy specimen. As a sensitive indicator of changes in villous architecture the index of the perimeter to lamina propria area was calculated for each specimen; the final index was the mean of all three measurements.

Statistical analysis was performed using the MannWhitney U test and Spearman's rank correlation test.
Results

Tables 1-3 show the results for the three groups and fig 2 shows a plot of the results.

\section{PERIMETER:LAMINA PROPRIA AREA INDEX}

Group 1 (patients with coeliac disease) and group 2 (patients with normal findings) showed the expected difference in the perimeter:lamina propria area index $\begin{array}{lllll}\text { (mean (SD) } & 0.018 \quad(0.0019) & \text { and } & 0.043 & (0.007)\end{array}$ respectively, $\mathrm{p}<0.001$ ). The mean (SD) perimeter:lamina propria area index in group 3 (patients with abnormal permeability and "normal" villi) was $0.035(0.003)$, which was significantly different from group $1(p<0.01)$ and group $2(0.01>p>0.001)$. There was a significant correlation between the perimeter:lamina propria area index and the cellobiose:mannitol ratio, (correlation coefficient $-0.57, p=0.001$ ) when all three groups were considered together.

\section{CELLOBIOSE ABSOR PTION}

Patients with coeliac disease absorbed more cellobiose than patients with normal findings (mean (SD) recovery $0.73 \%(0.52 \%)$ and $0.24 \%(0.18 \%)$ respectively, $\mathrm{p}=0.012$ ). There was a significant correlation between the perimeter:lamina propria area index and cellobiose absorption (correlation coefficient $-0.464, p=0.01$ ).

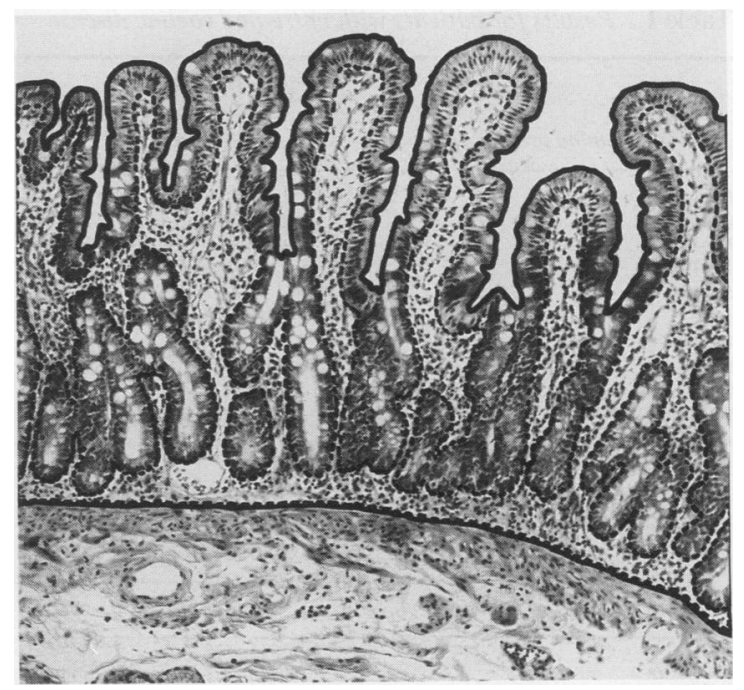

Fig 1 Image analysis measurements. Length of perimeter is given by tracing along surface epithelium, sides of field, and superficial aspect of muscularis mucosae (solid line). Area of lamina propria is contained by dotted line, which is a tracing around epithelial basement membrane and limits of mucosa. Areas occupied by cross sectioned crypts are deducted from total. 


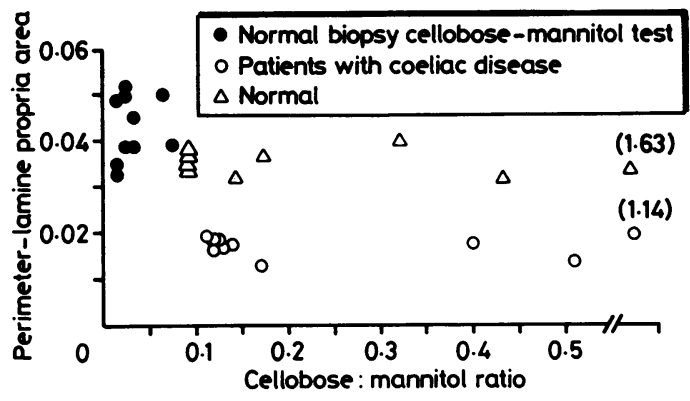

Fig 2 Cellobiose:mannitol ratio v perimeter:lamina propria area index for the three groups of patients.

\section{MANNITOL ABSORPTION}

Patients with coeliac disease absorbed significantly less mannitol (mean (SD) recovery 10.18\% (7.35\%)) than patients with normal findings (mean (SD) recovery $32.09 \%(29.96 \%))(p<0.01)$, but compared with cellobiose the correlation with the perimeter:lamina propria area index was less significant (correlation coefficient $0.376, p=0.04$ ).

Results for patients in group 3 were not significantly different from those for patients with coeliac disease: mean (SD) cellobiose absorption $0.74 \%(0.52 \%)$ and mean (SD) mannitol absorption $9 \cdot 7 \%(6 \cdot 07 \%)$.

Table 1 Results for patients with untreated coeliac disease

\section{Discussion}

This study shows that by using precise jejunal morphometry subtle architectural changes may be detected in patients thought to have normal jejunums but who have abnormal intestinal permeability. It also confirms that cellobiose absorption is increased and mannitol absorption decreased in patients with untreated coeliac disease compared with patients with normal jejunums. The mean mannitol absorption in the normal group of $32.09 \%$ was higher than expected since previous studies have shown a mean of about $20 \%$. $^{1{ }^{1011}}$ The higher value was a result of one subject having an aberrant mannitol value of $110.55 \%$. When this result was excluded the mean (SD) mannitol recovery fell to $23.37 \%(12.46 \%)$ and there was still a significant difference between patients with coeliac disease and those with normal findings $(\mathrm{p}<0.01)$. The cellobiose absorption was also high for this subject so that the final cellobiose:mannitol ratio fell within the normal range. This emphasises the advantage of expressing recoveries as a ratio, thereby eliminating the effect of extraneous factors acting similarly on both molecules.

The group of patients with abnormal cellobiose: mannitol ratios but who were considered to have normal jejunums on routine microscopical examination had cellobiose and mannitol absorption similar to those of patients with coeliac disease. There was a

\begin{tabular}{llll}
\hline & \multicolumn{2}{l}{$\%$} & \\
\cline { 2 - 4 } Perimeter:lamina propria area index & Cellobiose & Mannitol & Cellobiose:mannitol ratio \\
\hline 0.014 & 0.47 & 6.77 & 0.068 \\
0.016 & 1.27 & 6.25 & 0.204 \\
0.017 & 1.18 & 23.98 & 0.048 \\
0.018 & 0.16 & 2.95 & 0.052 \\
0.018 & 1.07 & 19.90 & 0.052 \\
0.018 & 0.96 & 16.85 & 0.056 \\
0.019 & 0.28 & 5.74 & 0.048 \\
0.019 & 1.52 & 6.43 & 0.160 \\
0.02 & 0.28 & 3.87 & 0.044 \\
0.02 & 0.17 & 0.456 \\
\hline
\end{tabular}

Table 2 Results for patients with normal findings

\begin{tabular}{|c|c|c|c|}
\hline \multirow[b]{2}{*}{ Perimeter:lamina propria area index } & \multicolumn{3}{|l|}{$\%$ recovery } \\
\hline & Cellobiose & Mannitol & Cellobiose:mannitol ratio \\
\hline $\begin{array}{l}0.033 \\
0.035 \\
0.039 \\
0.039 \\
0.039 \\
0.045 \\
0.049 \\
0.050 \\
0.050 \\
0.052\end{array}$ & $\begin{array}{l}0.68 \\
0.05 \\
0.10 \\
0.26 \\
0.05 \\
0.24 \\
0.15 \\
0.23 \\
0.5 \\
0.22\end{array}$ & $\begin{array}{c}110.55 \\
53.69 \\
11.29 \\
20.83 \\
12.21 \\
17.79 \\
25.06 \\
23.8 \\
20.31 \\
25.39\end{array}$ & $\begin{array}{l}0.004 \\
0.004 \\
0.008 \\
0.012 \\
0.028 \\
0.012 \\
0.004 \\
0.008 \\
0.024 \\
0.008\end{array}$ \\
\hline
\end{tabular}


Table 3 Results for patients with abnormal sugar test results and "normal" jejunums

\begin{tabular}{llll}
\hline & \multicolumn{2}{l}{$\%$ recovery } & \\
\cline { 2 - 4 } Perimeter:lamina propria area index & Cellobiose & Mannitol & Cellobiose:mannitol ratio \\
\hline 0.032 & 1.95 & 11.27 & $0 \cdot 172$ \\
0.032 & 0.91 & 16.84 & 0.056 \\
0.033 & 0.66 & 2.42 & 0.272 \\
0.034 & 0.66 & 18.63 & 0.036 \\
0.034 & 0.29 & 7.60 & 0.036 \\
0.037 & 0.55 & 14.62 & 0.036 \\
0.037 & 0.26 & 0.84 & 0.068 \\
0.037 & 0.46 & 10.97 & 0.652 \\
0.038 & 0.41 & 10.13 & 0.036 \\
0.04 & 1.31 & 0.128 \\
\hline
\end{tabular}

good correlation between the morphometric index and the sugar test result with a significant negative correlation between the perimeter:lamina propria area index and the cellobiose:mannitol ratio and between the cellobiose absorption and the perimeter: lamina propria area index; a significant positive correlation was found between mannitol absorption and the perimeter:lamina propria area index.

The relation between morphometry of small intestinal biopsy samples and permeability for sugars has been explored by Ford et al ${ }^{12}$ using a morphometric method described by Maluenda et al. ${ }^{13}$ Although these authors used computer based image analysis of tracings of the histological sections, only linear measurements of crypt depth, villous height, and villous height to crypt death ratio were used in their correlations. Ford et al found that abnormal morphology in duodenal biopsy samples was associated with increased permeability as assessed by differential sugar absorption ${ }^{12}$; in particular there was a strong correlation between crypt depth and permeability. Three of the twenty eight children undergoing biopsy, however, had normal histological appearances but abnormal sugar test results. The morphometric results in these children were not commented on, but the permeability changes were attributed to a more distal lesion.

Our method of computer assisted morphometry has been validated against both direct and stereological measurements. ${ }^{5}$ Indeed, we believe the computerised method to be superior to these other techniques because it is affected less by orientation and preparative artefacts than direct measurement and, futhermore, by sampling many more points it does not rely on the same statistical assumptions as stereology. The measurement of perimeter as opposed to surface length was originally dictated by software constraints in the IBAS2 mode, but as changes in perimeter are primarily a consequence of altered surface configuration and are affected little by variation in mucosal thickness or configuration of the muscularis mucosa we consider this a valid alternative.
In crypt hyperplastic villous atrophy the perimeter length decreases whereas the area occupied by lamina propria tends to increase so that the ratio of perimeter to lamina propria area becomes a highly sensitive index of altered villous architecture. The ratio perimeter:lamina propria area is closely correlated with the ratio of mucosal surface length to lamina propria area as measured in the non-interactive IBAS1 mode, ${ }^{5}$ but the latter method is more prone to tracing errors and in our hands showed wider intraobserver variation (unpublished observations).

The reason for using a hypertonic test solution is to increase discrimination between patients with coeliac disease and normal subjects, ${ }^{67}$ which is the purpose of this test when used generally. Hypertonicity increases cellobiose absorption in normal subjects, but to a greater degree in coeliac patients. Hypertonicity has no effect on mannitol absorption. ${ }^{2}$ This obviously differs from the physiological situation, but when similar tests were performed using an isotonic solution there was less discrimination and often no increase in recovery of the larger probe molecule in coeliac disease. ${ }^{121415}$ When mannitol is used as a probe molecule in isotonic solution it causes decreased absorption of disaccharides, an undesirable effect in this test. ${ }^{16}$

The 10 patients who had abnormal cellobiose: mannitol ratios and normal jejunums on routine histological examination underwent full examination of the gastrointestinal tract. The following diagnoses were made: idiopathic diarrhoea (four patients); abdominal pain of uncertain origin, probable irritable bowel syndrome (two patients); iron deficiency anaemia, cause unknown (one patient); weight loss, cause unknown (two patients); and postradiation enteritis (one patient). All 10 patients were discharged without symptoms after appropriate investigation, follow up, and treatment. The presenting symptoms in the "normal" group could have represented a secondary lactase deficiency but we would then have expected the cellobiose:mannitol ratio to be normal. ${ }^{2}$ In coeliac disease there is often a secondary 
disaccharidase deficiency, and since cellobiose is partially hydrolysed by the small intestine ${ }^{17}$ it has been suggested that the increased recovery of cellobiose may reflect cellobiase deficiency. ${ }^{3}$ In practice, there is no difference between urinary recoveries of cellobiose and lactulose (which is not hydrolysed ${ }^{18}$ ) in healthy subjects or patients with coeliac disease. ${ }^{19}$ Disaccharidase deficiency is therefore unlikely to play a part in the abnormal permeability in these patients.

It is possible that the abnormal cellobiose:mannitol ratios in the absence of coeliac disease were due to more distal disease, such as that in Crohn's disease, but there was no evidence to support this. The finding of subtle architectural disturbances as shown by generally reduced perimeter:lamina propria area indexes in this group is of clinical importance. When patients present with symptoms suggestive of coeliac disease but the jejunum appears normal, an abnormal cellobiose:mannitol ratio is normally regarded as a false positive result. This study, however, identified a group of patients with minor villous abnormalities not normally recognised on routine microscopical examination and which may account for the permeability changes and possibly the symptoms. It is unlikely that these patients are part of the range of coeliac disease because all 10 patients became symptom free without excluding gluten from their diet. Jejunal biopsies and cellobiose and mannitol tests were not repeated on these patients, and it is possible that the changes described are temporary and follow a transient insult to the intestinal mucosa resulting in permeability changes but only minor alterations in morphology.

Some other groups of patients have abnormal intestinal permeability in the absence of villous atrophy: these include patients with Crohn's disease, ${ }^{14} 20$ atopic eczema, ${ }^{21}$ or food allergy, ${ }^{22}$ and patients taking non-steroidal anti-inflammatory agents. ${ }^{23} 24$ Minor abnormalities in villous architecture similar to those found in this study might be found in these conditions if subjected to detailed morphometry.

This work indicates that an abnormal cellobiose: mannitol ratio is probably always associated with minor morphological abnormalities of the jejunal mucosa even though appearances on routine light microscopy are reported as normal.

\section{References}

1 Cobden I, Dickinson RJ, Rothwell J, Axon ATR. Intestinal permeability assessed by excretion ratios of two molecules: results in coeliac disease. Br Med J 1978;i:1060-1.

2 Cobden I, Hamilton I, Rothwell J, Axon ATR. Cellobiose/mannitol test: physiological properties of probe molecules and influence of extraneous factors. Clin Chim Acta 1985;148:53-62.

3 Menzies IS, Laker MF, Pounder R, et al. Abnormal intestinal permeability to sugars in villous atrophy. Lancet 1979; ii:1107-9.

4 Strobel S, Brydon WG, Ferguson A. Cellobiose/mannitol sugar permeability test complements biopsy histopathology in clinical investigation of the jejunum. Gut 1984;25:1241-6.

5 Corazza GR, Frazzoni M, Dixon MF, Gasbarrini G. Quantitative assessment of the mucosal architecture of jejunal biopsy specimens. A comparison between linear measurement, stereology, and computer-aided microscopy. J Clin Pathol 1985;38:765-70.

6 Menzies IS. Absorption of intact oligosaccharides in health and disease. Biochem Soc Trans 1974;2:1042-7.

7 Laker MF, Menzies IS. Increase in human intestinal permeability following ingestion of hypertonic solutions. J Physiol 1977;265:881-94.

8 Corcoran AC, Page IH. A method for the determination of mannitol in plasma and urine. $J$ Biological Chem 1947;170:165-71.

9 Menzies IS. Quantitative estimation of sugars in blood and urine by paper chromatography using direct densitometry. J Chromatography 1973;81:109-27.

10 Cobden I, Rothwell J, Axon ATR. Intestinal permeability and screening tests for coeliac disease. Gut 1980;21:512-8.

11 Hamilton I, Cobden I, Rothwell J, Axon ATR. Intestinal permeability in coeliac disease: the response to gluten withdrawal and single dose gluten challenge. Gut 1982;23:202-10.

12 Ford RPK, Menzies IS, Phillips AD, Walker-Smith JA, Turner MW. Intestinal sugar permeability: Relationship to diarrhoeal disease and small bowel morphology. Journal of Pediatric Gastroenterology and Nutrition 1985;4:568-74.

13 Maluenda C, Phillips AD, Briddon A, Walker-Smith JA. Quantitative analysis of small intestinal mucosa in cows milksensitive enteropathy. Journal of Pediatric Gastroenterology and Nutrition 1984;3:349-56.

14 Pearson ADJ, Eastham EJ, Laker MF, Craft AW, Nelson R. Intestinal permeability in children with Crohn's disease and coeliac disease. $\mathrm{Br}$ Med J 1982;285:20-1.

15 Menzies I, Noone C, Bull J, Mount JN. Discriminatory potential of sugar tests for detection of villous atrophy. Gut 1983; 24:A488.

16 Catt SD, Menzies IS, Segal MB. The effect of poorly absorbed solute on human intestinal absorption. J Physiol 1984;349:71P.

17 Dahlqvist A. Specificity of the human intestinal disaccharidases and the implications for hereditary disaccharide intolerance. $J$ Clin Invest 1962;41:463-70.

18 Dalqvist A, Grysboski JD. Inability of the human small intestinal lactase to hydrolyse lactulose. Biochim Biophys Acta 1965; 110:635-6.

19 Cobden I, Rothwell J, Axon ATR. Non-invasive test for small intestinal mucosal damage. Lancet 1979;ii: 1379.

20 Gomes M De FA, Dunne J, Logan LH, Pounder RE. Noninvasive assessment of small intestinal damage in Crohn's disease and ulcerative colitis. Gut 1983;24:A486.

21 Jackson PG, Lessof MH, Baker RWR, Ferrett J, Macdonald DM. Intestinal permeability in patients with eczema and food allergy. Lancet 1981;i:1285-6.

22 DuMont GCL, Beach RC, Menzies IS. Gastrointestinal permeability in food allergic eczematous children. Clin Allergy 1984;14:55-9.

23 Bjarnason I, Williams P, So A, Zanelli GD, Levi AJ, Gumpel JM, Peters TJ, Ansell B. Intestinal permeability and inflammation in rheumatoid arthritis: effects of non-steroidal antiinflammatory drugs. Lancet 1984;ii:1171-3.

24 Juby LD, Axon ATR, Wright V, Winstanley P, Rothwell J. Intestinal permeability and inflammation in rheumatoid arthritis. Br J Rheumatol 1986;25:226-7.

Requests for reprints to: Dr LD Juby, Gastroenterology Unit, The General Infirmary, Leeds LS1 3EX, England. 